\section{THE IMPACT OF ADVERSE CHILDHOOD EXPERIENCES ON HEALTH: A SYSTEMATIC REVIEW AND META- ANALYSIS}

${ }^{1}$ Karen Hughes, ${ }^{1}$ Katie Hardcastle, ${ }^{1,2}$ Mark A Bellis. ${ }^{1}$ WHO Collaborating Centre for Violence Prevention, Liverpool John Moores University, UK; ${ }^{2}$ Public Health Wales, UK

\subsection{6/injuryprev-2016-042156.286}

Background A growing number of studies are seeking to examine the long-term impacts of adverse childhood experiences (ACEs; including child maltreatment and exposure to family violence and other household dysfunction in childhood) on health and wellbeing. Synthesis of such studies is needed to provide policymakers and practitioners with evidence to support investment in effective prevention and support strategies.

Methods We undertook a systematic literature search to identify studies that measured the cumulative impact of ACEs on health harming behaviours (HHBs) and health outcomes in adulthood. Included studies measured at least four ACEs (covering both child maltreatment and dysfunctional family environments) and permitted the measurement of odds ratios for outcome measurements by ACE count up to $4+$ ACEs. Data were extracted from included studies for outcomes relating to: violence; substance use; sexual behaviour; weight and exercise; mental health (including suicide); and chronic diseases. Meta-analyses were undertaken for outcomes covered by at least four studies.

Results Meta-analyses found a cumulative impact of ACEs on most outcomes measured, with risks (pooled odds ratios) increasing with ACE counts. Outcomes with the greatest impacts included self-directed violence; violence perpetration; violence victimisation; and problem alcohol and drug use.

Conclusions The cumulative relationship between ACEs and a wide variety of health and social outcomes is being identified in populations across the globe. Developing multi-agency understanding of the links between ACEs and adult outcomes is imperative to support the implementation of effective action to prevent child maltreatment, promote family wellbeing and support those affected by childhood adversity to ultimately prevent violence and improve population health.

\section{ACTION TO PROMOTE POPULATION SURVEYS OF CHILD MALTREATMENT IN EUROPEAN COUNTRIES}

'Dinesh Sethi, ${ }^{2}$ Franziska Meinck. 'WHO Regional Office for Europe, Copenhagen, Denmark; ${ }^{2}$ Oxford University, United Kingdom

\subsection{6/injuryprev-2016-042156.287}

Background The European report on preventing child maltreatment reported a prevalence of $9.6 \%$ for child sexual abuse, $22.9 \%$ for physical abuse, $29.1 \%$ for mental abuse. It is estimated that $90 \%$ of abuse and neglect goes undetected. Investing in Children: the European Child Maltreatment Prevention Action Plan 2015-2020 has an aspirational target to reduce child maltreatment by $20 \%$. Progress towards this can only be demonstrated if reliable indicators are used for monitoring. However, only $60 \%$ of countries reported that they had conducted population surveys of child maltreatment in European facts and the Global status report on violence prevention 2014. This paper describes the actions being undertaken by the World Health Organisation to improve surveillance of child maltreatment.

Methods A comprehensive review of the literature was conducted to identify instruments used in population surveys of child maltreatment. A total of 34 instruments were identified, and were further shortlisted on the basis of published data on validity and reliability, licensing and copyright restrictions and user fees. On this basis 4 instruments were selected for psychometric testing. These were the IPSCAN Child Abuse Screening Tools (ICAST), Juvenile Victimisation Questionnaire (JVQ), Parent-Child Conflict Tactics (PCCT) questionnaire and the Adverse Childhood Experiences (ACE) questionnaire.

Results Study data gathered in population surveys that have used the four instruments (I-CAST, JVQ, PCCT, ACE) have been requested from investigators. Psychometric testing is being applied to these datasets in order to propose one instrument for future studies and to develop a short form for inclusion in already planned surveys such as the Demographic and Health Surveys and the Multiple Indicator Cluster Surveys. These results and their implications will be discussed.

Conclusions A handbook is being developed to promote population surveys of child maltreatment in Member States. This will contain guidance on surveys, advice on instruments of choice for bespoke population surveys, and a short form instrument for proposed inclusion in already planned surveys. The handbook will be disseminated to health ministry focal points for violence prevention and other stakeholders. This tool is being developed as a means of assisting practitioners to conduct standardised population surveys of child maltreatment. The implications of this will be discussed in relation to European Child Maltreatment Prevention Action Plan.

\section{INTER-RATER RELIABILITY OF CHILD DEATH REVIEW TEAM CLASSIFICATION OF CHILD MALTREATMENT}

${ }^{1,2}$ Jared W Parrish, ${ }^{3}$ Teresa M Covington, ${ }^{3}$ Patricia G Schnitzer, ${ }^{2}$ Stephen W Marshall. ${ }^{1}$ Alaska Division of Public Health, USA; ${ }^{2}$ The University of North Carolina at Chapel Hill, USA; ${ }^{3}$ The National Centrefor Fatality Review, USA

\subsection{6/injuryprev-2016-042156.288}

Background The US Child Death Review (CDR) multi-disciplinary team consensus process uses tiered maltreatment definitions that allow for a degree of uncertainty. Individual heterogeneity is thought to normalise within the context of the CDR team resulting in reliable consensus determinations. This assumption has never been tested. The Alaska CDR tiered maltreatment designations were used to assess the polytomous maltreatment classification.

Methods We used a mixed-methods inter-rater reliability framework to test the reliability of abuse, neglect, and gross-negligence classifications through CDR consensus review. All children born in 2009-10 who died in Alaska through 2014 were eligible for inclusion $(\mathrm{n}=116)$; after exclusions 101 cases were re-reviewed. Approximately half of the cases were included with normal monthly reviews, the rest were reviewed at an annual committee "blitz" review.

Results Total percent agreement was $64.7 \%$ with a weighted Kappa of 0.61 (95\% CI: $0.51,0.70)$. The percent agreement was $69.3 \%$ for abuse, $64.4 \%$ for neglect, and $60.4 \%$ for gross-negligence. Agreement was much less among infant deaths compared to child deaths ( 0.48 vs $0.77 ; \mathrm{p}=0.001)$ and unmarried mothers at birth $(0.47$ vs $0.74 ; p=0.005)$. Incidence estimates per 1,000 live births are statistically equivalent between the initial and subsequent review for yes/yes probably any maltreatment and by maltreatment type.

Conclusions This is the first known reliability study of CDR team classification of tiered maltreatment death classification. Not unexpectedly, substantial agreement was observed for abuse 
and only moderate agreement for neglect and negligence classifications. Discordance is related to missing or unknown information and the interpretation of identified risk factors. Due to these limitations, standardised death scene investigations for all infant and child deaths are invaluable and implementing a systematic decision tree metric is necessary to produce more reliable estimates.

\section{EFFECTIVE METHODS FOR IDENTIFYING CHILD MALTREATMENT WITHIN THE FAMILY - NATIONAL CLINICAL GUIDELINE}

1,2Eija Paavilainen, ${ }^{1,3}$ Aune Flinck. 'University of Tampere, Finland; ${ }^{2}$ Etelä-Pohjanmaa
Hospital District, Finland; ${ }^{3}$ National Institute of Health and Welfare, Finland

10.1136/injuryprev-2016-042156.289

Background Child maltreatment (physical or psychological abuse or neglect of young people, under 18 years of age) is a sensitive and complex issue both in terms of clinical practice and research. It is a matter of concern for both child protective services and health services and in all services dealing with children, and families with children.

Objective of our systematic review was to synthesise the best available evidence regarding the effectiveness of methods in identifying child maltreatment. The National Clinical Guideline (www.hotus.fi) was updated in 2015, based on the systematic review.

Results Risk factors concerning the child, parents ad the family situation are presented. Methods for the examination, identification, and evaluation of rib fractures, abdominal injuries, bruises, and burns were found. Screening tools have been developed especially for emergency care and risk assessment. Evidence of the need to develop multiprofessional practice services (including policy and organisational development) was found. Educating staff concerning child maltreatment issues was found to be effective. Guidelines based on this evidence are presented.

Conclusions Methods for identification are often insufficient. However, several useful methods and tools were found. Professionals need continuous training, clinical supervision, attitude change at the individual level, and coherent tools to identify risks and cases of maltreatment and family violence in general. From the effectiveness point of view, research has been made to some degree so far.

\section{Pedestrian and Cyclists Safety}

\section{Parallel Tue 2.3}

\section{DEVELOPMENT AND EVALUATION OF A SOCIAL MARKETING APPROACH TO REDUCE PEDESTRIAN INJURY RISK}

Andrea Gielen, Maryanne Bailey, Keshia Pollack, Eileen McDonald, Jim Williams. Johns Hopkins Centre for Injury Research and Policy, USA

\subsection{6/injuryprev-2016-042156.290}

Background Pedestrian injuries continue to be an intractable global public health. Engineering changes and enforcing traffic laws have considerable evidence supporting their effectiveness. Also important but less well understood is how to influence pedestrian and driver behaviour through educational campaigns.
Our purpose is to describe how we developed, implemented and evaluated a social marketing campaign to address this gap.

Methods The site was an urban academic medical centre campus where large numbers of students, staff, patients, and visitors drive and walk daily. Formative research included focus groups with the target audience. A two-phase, six-month campaign targeted both drivers and pedestrians, and was based on social marketing concepts of product, price, promotion, and place. Evaluation included baseline, mid-term, and follow-up online surveys of campus and community respondents. We analysed the proportion who reported: 1) exposure to the campaign and their reactions to it; and 2) driving and street crossing behaviours.

Results Online survey sample sizes were 3,928 at baseline, 2,705 at mid-term, and 3,017 at follow-up. At mid-term 82\% reported having seen campaign materials and at follow-up this $\%$ was 78 . At both time points the majority of respondents $(\geq 70 \%)$ rated the campaign positively. At follow-up the proportion reporting they often looked both ways before crossing an intersection was $94.5 \%$ for those reporting exposure to the campaign and $88.1 \%$ for those reporting no exposure to the campaign. The proportion reporting they often drove slowly through intersections to look for pedestrians was $50 \%$ for those reporting exposure to the campaign and $42 \%$ for those reporting no exposure to the campaign.

Conclusions Few pedestrian safety campaigns are systematically planned and evaluated. This work (which includes a free dissemination guide) provides a roadmap to developing such interventions, and results show promise for enhancing individuals' safety.

\section{PEDESTRIAN ADOLESCENTS: MOBILITY AND SAFETY AT SECONDARY SCHOOL IN FRANCE}

${ }^{1}$ Marie-Axelle Granié, ${ }^{1}$ Thierry Brenac, ${ }^{2}$ Florence Huguenin-Richard, ${ }^{3}$ Thierry Saint-Gérand, ${ }^{3}$ Mohand Medjkane, ${ }^{1}$ Elisa Maître, ${ }^{1}$ Jean-François Peytavin, ${ }^{4}$ Florent Varet, ${ }^{1}$ Cécile Coquelet. 'IFSTTAR-TS2-LMA, France; ' ${ }^{3}$ nniversity of Paris Sorbonne, France; ${ }^{3}$ University of Caen, France; ${ }^{4}$ Aix-Marseille University, France

\subsection{6/injuryprev-2016-042156.291}

Background The road crash peak among children is around 1112 years-old in France, as in many industrialised countries, at the time of entry in secondary school. The reasons why this vulnerability increases while the skills involved should have improved are not clear.

By linking two fields of analysis of road safety (fine spatial analysis of crashes and depth analysis of behaviours and psychosocial factors), our project aimed to finely identify the mobility and pedestrian accident involvement of the 10-15 years old and specify geographical, psychological and sociological determinants of both variables.

Methods and results A study of accident processes among pedestrians aged 10-15 years over France for the period 2002-2011 was conducted, based on the national accident file and on a sample of accident police reports. It was completed in the field of study of the Lille region (France) by the spatial analysis of local accident data (including the identification of accident scenarios) and the mobility of 10-15 years, using data from the 2006 household travel survey.

Two field surveys were then conducted. A first survey among 2500 junior high school students has identified the fine mobility practices and their socio-spatial determinants. It also explored the demographic and psychological variables (age, gender roles, perceptions of social norms, risks, rules, level of supervision) explaining the reported pedestrian risky behaviours. A second 